\title{
Sexuality in young patients with Parkinson's disease: a population based comparison with healthy controls
}

\author{
Helfried Jacobs, Alexandra Vieregge, Peter Vieregge
}

\begin{abstract}
Answers from a multiple choice questionnaire on the opinions about public sexual attitudes, on emotion from personal sexual practice, on personal sexual function, and on general health perception were compared between 121 patients with Parkinson's disease (mean age 45 years) and 126 age and sex matched community derived controls. Patients were more dissatisfied with their present sexual functioning and relationship, and perceived their general health as poorer than the controls, whereas opinions about public sexual attitudes were only marginally different. No differences were found for sexual function. Further analysis showed that the perception of sexual functioning and general health in younger patients with Parkinson's disease is considerably influenced by depression and state of unemployment.
\end{abstract}

(F Neurol Neurosurg Psychiatry 2000;69:550-552)

Keywords: Parkinson's disease; sexuality; depression; quality of life

Until today, it is unclear whether patients with Parkinson's disease differ in sexuality from healthy people of similar age. ${ }^{1-5}$ One reason for this ambiguity is that most earlier studies have methodological restrictions (inclusion of exclusively men, ${ }^{4}$ women, ${ }^{5}$ spouses as controls ${ }^{2}{ }^{3}$ ). We therefore studied sexuality in a group of younger patients with Parkinson's disease and compared the findings with a community derived matched control group of healthy people.

Neurology, Medical

University of Lübeck,

Ratzeburger Allee 160, D-23538 Lübeck,

Germany

H Jacobs

A Vieregge

P Vieregge

Correspondence to: Professor Peter Vieregge vieregge_p@
neuro.mu-luebeck.de

Received 8 September 1999 and in revised form

2 May 2000

Accepted 17 May 2000 domly drawn from the community registry of the City of Lübeck. For each patient, four healthy people were asked by letter to participate. If the control did not respond to the first letter, a reminding letter was sent 2 weeks later. In cases of no response, a third and final letter, again sent 2 weeks later, asked for reasons of non-participation. Participants were requested to answer to the study centre by letter or phone. On this occasion, they could ask questions about the study. For participation, all subjects had to give their written informed consent. The study was approved by the medical ethics committee of the Medical University of Lübeck and the data protection specialist of the Province of Schleswig-Holstein.

During the visit the physician investigator (HJ) examined the patients personally. $\mathrm{He}$ reviewed the medical records of treating physicians. Parkinson's disease was defined according to the United Kingdom Parkinson's Disease Society brain bank criteria. ${ }^{6}$ In all patients the motor part of the unified Parkinson's disease rating scale ${ }^{7}$ and the Hoehn and Yahr score $^{8}$ were determined. Patients and controls then had a structured interview about disease variables and sociodemographic data that was followed by a multiple choice questionnaire about sexuality. ${ }^{9}$ Arranged in random order, 33 items covered opinions about public sexual attitudes (eight questions), emotion from personal sexual practice (18 questions), intercourse frequency as a measure of sexual function (four questions), and general health perception (three questions). Participants had to fill in the questionnaire while the investigator was present. To assess educational influences the short form of the Wechsler adult intelligence scale ${ }^{10}$ (subtests information, similarities, picture completion, and block design) was applied. Depressive mood was assessed with the paranoid-depression scale, ${ }^{11}$ a standardised German questionnaire listing 43 statements that in random order cover feelings and thoughts of paranoia, depression, and denial of psychiatric illness. The degree of agreement to every item has to be graded by the subject into one of four categories (applies definitely; applies mostly; applies somewhat; does not apply). Raw scores were transformed into sex corrected $\mathrm{T}$ values normalised for German 
Table 1 Disease indices, sociodemographic variables, and neuropsychological test results in 121 patients with Parkinson's disease and 126 controls

\begin{tabular}{|c|c|c|}
\hline & Patients & Controls \\
\hline$\overline{\text { Men }}$ & $70(58)$ & $68(54)$ \\
\hline Mean age $(y)$ & 44.9 (SD 4.0) & $43.8($ SD 4.6$)$ \\
\hline Mean age of PD onset (y) & 36.4 (SD 7.2 ) & \\
\hline Mean disease duration (y) & $8.1(\mathrm{SD} 6.4)$ & \\
\hline \multicolumn{3}{|l|}{ Hoehn and Yahr stage } \\
\hline I & $27(22)$ & \\
\hline II & $36(30)$ & \\
\hline III & 47 (39) & \\
\hline IV & $11(9)$ & \\
\hline Mean UPDRS-III score & $25(\mathrm{SD} 14)$ & \\
\hline Mean daily levodopa dosage (mg) & $394(\mathrm{SD} 232)$ & \\
\hline \multicolumn{3}{|l|}{ No of patients treated with: } \\
\hline Dopamine agonists & $108(89)$ & \\
\hline MAOB inhibitors & $24(20)$ & \\
\hline Anticholinergics & $27(22)$ & \\
\hline COMT inhibitors & $34(28)$ & \\
\hline Antidepressants & $23(19)$ & \\
\hline Unmarried & $15(12)$ & $8(6)$ \\
\hline At least one child & $99(82)$ & $99(79)$ \\
\hline \multicolumn{3}{|l|}{ School years } \\
\hline 8 & $46(38)$ & $51(41)$ \\
\hline 10 & $35(29)$ & $50(40)$ \\
\hline 13 & $40(33)$ & $25(20)$ \\
\hline Currently employed & $50(41)^{\star}$ & $102(81)$ \\
\hline Median IQ (WAIS) & 99 & 101 \\
\hline \multicolumn{3}{|l|}{ Median depression score } \\
\hline Men & $62.6^{\star}$ & 52.9 \\
\hline Women & $60.8^{\star}$ & 50.1 \\
\hline
\end{tabular}

${ }^{\star} \mathrm{p}<0.05$. Values in parentheses are $\%$ unless stated otherwise.

adults. T Values above 56.3 (women) and 56.8 (men) indicate substantial depression. $\chi^{2}$ Analysis and Student's $t$ test were performed using the statistical package for the social sciences (SPSS-PC). Statistical significance was assumed at $p<0.05$. Stratified samples were analysed by $2^{\star} \mathrm{k}$ comparison of cross tables. ${ }^{12}$ Here, statistical significance was assumed at $\mathrm{p}<0.01$.

\section{Results}

Two hundred and eighty patient members of the lay organisation were approached, another 13 patients were asked during local gatherings of the organisation. Ninety five patients were addressed from physician lists. Of these 388 patients, 163 agreed to participate (121 association members (43\%); 42 patients from physician lists $(44 \%))$. Sixteen patients refused (all association members), 209 did not answer (155 association members (55\%); 54 patients from physician lists $(56 \%))$. Thirty four patients were excluded because they were located too far away. Eight patients were excluded because they did not fulfil the study criteria, leaving 121 patients who completed the questionnaire. Of the 508 controls approached, 128 (25\%) agreed to participate, $194(38 \%)$ refused, and $186(37 \%)$ never responded. Two controls withdrew during the investigation, leaving 126 controls who completed the questionnaire.

Sociodemographic data are shown in table 1. All subjects reported to presently live in a heterosexual partnership. Significantly more patients than controls were currently unemployed and had depression. Patients more often disagreed about the present attitude of most people towards sexuality (table 2). Patients also disapproved of homosexuality more often. More patients than controls indicated dissatisfaction with their current sexual life. Dissatisfied patients ( $\mathrm{T}$ value of depression score 66.9 (SD 9.1)) showed more depression than satisfied patients ( $\mathrm{T}$ value 59.7 (SD 8.4); $\mathrm{p}<0.01$ ). Also, dissatisfied patients were more often men than women $(36 \% v 20 \% ; \mathrm{p}<0.01)$. No such differences were seen among the control persons. Depressed and unemployed patients were more often dissatisfied with their present sexual relationship, less able to enjoy a small flirtation, and felt lonely more often $(\mathrm{p}<0.01$, each). Frequency of intercourse was not different between groups. Patients were more often dissatisfied with their life so far, felt older than their present age, and perceived their current health as worse than the controls. Perceived current health status was worse in patients with depression and unemployment ( $p<0.01$ each). No other demographic or disease variable was related to the answer pattern.

\section{Discussion}

Opinions about public sexual attitudes and the emotion from personal sexual practice were only slightly different between younger patients

Table 2 Opinions about public attitudes towards sexuality, emotion from own sexual practice, personal sexual function, and general health perception in 121 patients with Parkinson's disease and 126 controls. For each category, the numbers of responses from patients and controls $(x / y)$ are given

\begin{tabular}{|c|c|c|c|c|}
\hline Opinions & Positive & Negative & Neither-nor & No answer \\
\hline Living together of unmarried young couples? & $106 / 122$ & $5 / 2$ & - & $10 / 2$ \\
\hline Should law facilitate divorce? & $52 / 68$ & $7 / 2$ & $42 / 46$ & $20 / 10$ \\
\hline Attitude towards sexual relationship outside marriage? & $58 / 69$ & $43 / 28$ & $15 / 23$ & $5 / 6$ \\
\hline People's attitudes towards sexuality nowadays? & $100 / 118$ & $11 / 4^{\star}$ & $6 / 1$ & $4 / 3$ \\
\hline Homosexuality? & $63 / 81$ & $26 / 9^{\star}$ & $24 / 30$ & $8 / 6$ \\
\hline Emotion & Yes & No & Neither-nor & No answer \\
\hline Sexual life as satisfying now as in the past? & $95 / 112$ & $20 / 7^{\star \star \star}$ & - & $6 / 7$ \\
\hline Sometimes watching erotic films? & $91 / 97$ & $24 / 23$ & - & $6 / 6$ \\
\hline Caring for looking attractive? & $100 / 115$ & $11 / 9$ & - & $10 / 2$ \\
\hline Enjoy a small flirtation? & $96 / 113$ & $21 / 9 \star \star$ & - & $4 / 4$ \\
\hline Can imagine sex without marriage? & $19 / 14$ & $94 / 104$ & - & $8 / 8$ \\
\hline Sexuality important part of life in the past? & $63 / 57$ & $48 / 57$ & - & $10 / 12$ \\
\hline Feeling lonely sometimes? & $56 / 23$ & $59 / 102^{\star \star \star}$ & - & $6 / 1$ \\
\hline Satisfied with present sexual relationship? & $67 / 88$ & $25 / 12^{\star \star}$ & $19 / 20$ & $10 / 6$ \\
\hline Sexual function & Yes & No & Neither-nor & No answer \\
\hline Presently as much or more intercourse as 10 years ago? & $48 / 60$ & $60 / 53$ & - & $13 / 13$ \\
\hline Frequency of sexual intercourse $2-3$ times a week? & $34 / 44$ & $73 / 68$ & - & $14 / 14$ \\
\hline Health perception & Yes & No & Neither-nor & No answer \\
\hline \multirow[t]{2}{*}{ Satisfied with life so far? } & $68 / 106$ & $21 / 4^{\star \star \star}$ & $25 / 14$ & $7 / 2$ \\
\hline & Younger & Older & Neither-nor & No answer \\
\hline \multirow[t]{2}{*}{ Feeling younger/older than present age? } & $57 / 76$ & $20 / 5^{\star \star \star}$ & $4 / 2$ & $40 / 43$ \\
\hline & Good & $\mathrm{Bad}$ & Neither-nor & No answer \\
\hline Selfperceived state of current health? & $26 / 98$ & $29 / 5^{\star \star \star}$ & $6 / 3$ & $60 / 20$ \\
\hline
\end{tabular}

${ }^{\star} \mathrm{p}<0.05 ;{ }^{\star \star} \mathrm{p}=0.02 ;{ }^{\star \star \star} \mathrm{p} \leqslant 0.01$

Hyphen indicates that "neither-nor" was not given as a choice in the respective question. 
with Parkinson's disease and healthy controls living in the community. By contrast with previous data, sexual dissatisfaction did not increase with duration or severity of Parkinson's disease in our patients. ${ }^{1}$ On the measure of change in sexuality we did not propose a time frame: respondents were simply asked whether or not "sexuality is as satisfying now as in the past". However, responses on frequency of intercourse did not differ for either " 10 years ago" or "currently". It seems unlikely, therefore, that the lack of a defined time frame for measuring a change in sexuality has distorted our results. Our data underline that sexual problems in Parkinson's disease may particularly arise in couples where the patient is male $^{2}$ : Only in the patient group were male but not female respondents dissatisfied with their current sexual relationship. We were able to substantiate the earlier assumption ${ }^{2}$ that the male bias in distribution of sexual difficulties is related to state of employment. In patients with Parkinson's disease, unemployment seems as important as depression in determining the answer pattern about satisfaction with sexuality and personal life as yet. Both factors also relate to the worse perception of general health in the patients.

Our study has strengths and limitations. Firstly, all patients were examined by always the same investigator according to defined criteria and to an established procedure. By cross checking patient diagnoses and clinical records, we were able to obtain a high level of consistency for data collection and diagnosis of Parkinson's disease. Secondly, as a result of our case ascertainment, patients with mild disease may be underrepresented, whereas more severely ill patients - that is, patients with a longer disease duration and more depressionmay be overrepresented. Also, depressed patients with a chronic condition are likely to care more for their health than non-depressed patients. ${ }^{13}$ They are, therefore, more likely to participate in studies such as the present one. The overall proportion of depressive patients was high compared with earlier studies about sexuality in Parkinson's disease. ${ }^{1245}$ It was also higher than in a recent population study on depression in Parkinson's disease. ${ }^{14}$

Thirdly, three quarters of our patients were members of a lay organisation for Parkinson's disease. Thus, selection bias towards the well informed may have been introduced. However, our results were remarkably independent of educational level. Fourthly, the rates of participation in patients and controls were low. But with a proportion of $81 \%$ of regular employment and almost equally distributed levels of education, our control group appeared as a representative sample of the normal population. Fifthly, self selection cannot be ruled out. However, all people taking part in the entire study on sociodemographic variables and risk factors of Parkinson's disease answered the questionnaire about sexuality. This questionnaire was not explicitly announced as part of the study during proband recruitment. Therefore, a selection bias for participation in only this questionnaire seemed to be unlikely. Sixthly, the absolute numbers in some questionnaire responses were admittedly small. Conclusions from our results should therefore be drawn cautiously. Nevertheless, our data appeared consistent throughout.

Taken together, our study confirms that depression in patients with somatic disorders is more relevant to the subjective sense of dissatisfaction with their sexuality rather than physiological dysfunction ${ }^{15} 16$ and that depressive mood significantly influences the answer pattern in inquiries about sexuality in patients with Parkinson's disease. Unemployment as another determining factor points to complex mutual effects of psychosocial factors on sexuality in younger patients. Physicians should consider psychological rather than somatic intervention in younger patients with Parkinson's disease who are dissatisfied with their sexual life.

We thank many colleagues for their help in patient recruitment, and Dr L Wermuth for sending us the questionnaire from her earlier investigation. Partial financial support from the German Parkinson's Disease Association is kindly acknowledged.

1 Wermuth L, Stenager E. Sexual problems in young patients with Parkinson's disease. Acta Neurol Scand 1995;91:453-

2 Brown RG, Jahanshahi M, Quinn N, et al. Sexual function in patients with Parkinson's disease and their partners. $7 \mathrm{Neu}$ rol Neurosurg Psychiatry 1990;53:480-6.

3 Koller WC, Vetere-Overfield B, Williamson A, et al. Sexual dysfunction in Parkinson's disease. Clin Neuropharmacol 1990;5:461-3.

4 Lipe H, Longstreth WT, Bird TD, et al. Sexual function in married men with Parkinson's disease compared to married men with arthritis. Neurology 1990;40:1347-9.

5 Welsh M, Hung L, Waters CH. Sexuality in women with Parkinson's disease. Mov Disord 1997;6:923-7.

6 Gibb WRG, Lees AJ. The relevance of the Lewy body to the pathogenesis of idiopathic Parkinson's disease. $\mathcal{F}$ Neurol Neurosurg Psychiatry 1988;51:745-52.

7 Fahn S, Elton RL, Members of the UPDRS Development Committee. Unified Parkinson's disease rating scale. In: Fahn S, Marsden CD, Goldstein M, eds. Recent developFahn S, Marsden CD, Goldstein M, eds. Recent develop-
ments in Parkinson's disease II. Florham Park: Macmillan, 1987:153-63.

8 Hoehn MM, Yahr MD. Parkinsonism: onset, progression, and mortality. Neurology 1967;17:427-42.

9 Schneider HD. Sexualverhalten in der zweiten Lebenshälfte: Ergebnisse sozialwissenschaftlicher Forschung. Stuttgart: Kohlhammer Verlag, 1980

10 Wechsler D. Handanweisung zum Hamburg-WechslerIntelligenztest für Erwachsene (HAWIE). Bern: Hans Huber Verlag, 1982.

11 Zerssen D von, Koeller DM. Paranoid-Depressivitäts-Skala. Weinheim: Beltz Test, 1976.

12 Sachs L. Angewandte Statistik. 4. Auflage. Berlin: Springer Verlag, 1973:357-66.

13 Smith GR. The epidemiology and treatment of depression when it coexists with somatoform disorders, somatization, when it coexists with somatoform disorders, som

14 Tandberg E, Larsen JP, Aarsland D, et al. Risk factors for depression in Parkinson disease. Arch Neurol 1997;54:62530 .

15 Nofzinger EA, Thase ME, Reynolds CF, et al. Sexual function in depressed men. Assessment by self-report, behavio$\mathrm{ral}$, and nocturnal penile tumescence measures before and after treatment with cognitive behavior therapy. Arch Gen Psychiatry 1993;50:24-30.

16 Monga TN, Tan G, Ostermann HJ, et al. Sexuality and sexual adjustment of patients with chronic pain. Disabil Rehabil 1998;20:317-29. 